\title{
PRINCIPLES OF CLASSIFICATION OF BOOK ADVERTISING GENRES
}

\author{
Tatyana V. Anisimova \\ Volgograd State University, Volgograd, Russian Federation
}

\begin{abstract}
The article deals with the relevant classifications of advertising genres. The author believes that the use of such classifications should take into account the features of the advertised product, as the genre composition of advertisements of different product groups differs substantially. It is shown, that in book advertisement the main form of promotion is represented by a modified abstract, and in its original form it is only used to promote educational literature. In other cases, it is a form of genre imitation, either directly or indirectly associated with the advertised kind of literature, and in this case, it is not only the genre's general structure, but also the peculiarities of linguistic realization of the text corresponding to the functional style. The article analyzes the forms of stylization which are peculiar for advertising art and religious literature as well as non-fiction works about business, healthy life style, psychology, fashion, etc. As a result, the author identifies two main groups of such stylizations: 1) stylization to the books' genres (short story - for fiction, sermon - for religious literature, etc); 2) stylization to the genres, explicitly designed to endorse the content of the advertised literature (review - for fiction, customer reviews - for literature about the business, healthy life style, etc.).
\end{abstract}

Key words: genres of advertising, book advertising, styling, classification of genres, abstract, stylistic features of advertising.

УДК 81:347.777:791.22

Дата поступления статьи: 29.08.2016

ББК 81.055.51.6

Дата принятия статьи: 01.11.2016

\section{ПРИНЦИПЫ КЛАССИФИКАЦИИ ЖАНРОВ РЕКЛАМЫ КНИГИ}

\section{Татьяна Валентиновна Анисимова}

Волгоградский государственный университет, г. Волгоград, Российская Федерация

\footnotetext{
Аннотация. В статье анализируются распространенные в настоящее время классификации жанров рекламы. Автор доказывает, что при составлении таких классификаций необходимо учитывать особенности рекламируемого товара, поскольку жанровый состав рекламы различных групп товаров имеет весьма существенные отличия. Показано, что в рекламе книги основной формой продвижения является модифицированная аннотация, причем для усиления воздействующей функции ей чаще всего придается форма стилизации под жанры, прямо или косвенно связанные с видом рекламируемой литературы. В статье анализируются формы стилизации, характерные для рекламы художественной и религиозной литературы, а также нехудожественных произведений о бизнесе, здоровом образе жизни, психологии, моде и т. п. В результате автором выделяются две основные группы таких стилизаций: стилизация под жанры, характерные для того вида литературы, к которому относится сама книга (рассказ для художественной литературы, проповедь для религию озной литературы и т. п.); стилизация под жанры, прямо предназначенные для одобрения содержания рекламируемого вида литературы (рецензия для художественной литературы, отзывы клиентов для литературы о бизнесе, здоровом образе жизни и т. п.).

Ключевые слова: жанры рекламы, реклама книги, стилизация, классификация жанров, аннотация, стилистические особенности рекламы.
} 


\section{1. Традиционные классификации жанров рекламы}

Проблема классификации жанров рекламы до сих пор стоит очень остро. Несмотря на большой интерес исследователей к этому феномену и разнообразие вышедших за последние годы работ, споры по этому поводу не утихают.

В основании системы представлений о жанровой природе рекламных посланий лежат концепции, частично актуальные до настоящего времени.

1.1. Рекламу (по крайней мере товарную рекламу) следует считать одним жанром, а все различия, связанные с объемом текста, носителем, на который она помещается, и т. п., признать внутрижанровыми разновидностями. Эта точка зрения имеет право на существование, поскольку, действительно, все основные характеристики жанра (предмет, субъект, адресат, задача и даже основные стратегии воздействия) для всех рекламных форм практически идентичны. Ср.: «Жанр рекламы рассматривается нами как особый жанр публичной речи, выполняющий двуединую - информационносодержательную и воздействующую - функцию. В зависимости от предмета рекламы, адресата рекламного текста и авторских интенций рекламный жанр выступает как комплексный, включающий целый ряд атомарных речевых жанров» [6, с. 158]. Вместе с тем понятие жанра требует единства не только содержания, но и формы текста, а здесь разнообразие образцов так велико, что не дает возможности согласиться с тем, что все это одежды одного и того же жанра.

1.2. Жанры рекламы сводятся к жанрам публицистики: рекламная заметка, рекламный очерк, рекламный репортаж, рекламное интервью и т. п. Эта классификация появилась еще в 70-е гг. XX в. и характеризует в большей степени советскую рекламу, которая ограничивалась публикацией в прессе информационно-рекламных материалов. В настоящее же время разнообразие форм уже так велико, что перечисленные жанры составляют только незначительный сегмент (причем периферийный) общей классификации жанровых форм рекламного послания. Однако старая концепция продолжает жить и приводится как актуальная даже в справочниках по коммуникации: «По своему жанру рекламные тексты делятся на следующие разновидности: рекламное объявление, заметка, статья, рецензия, интервью, корреспонденция, репортаж, консультация, рассказ, отчет, выступление» $[10$, c. 712$]$.

1.3. Первая попытка создания современной классификации жанров рекламы была предпринята, как известно, в пособии, выпущенном Академией рекламы [11, с. 18-44]. Здесь предложен принцип классификации, весьма активно применяемый до сих пор - в зависимости от того, в каком виде СМИ эти формы используются (теле-, радио-, печатная реклама и т. д.). Указанное основание должно быть признано важным (существенным) и обязательно учтено при построении классификации жанровых форм рекламы, однако оно не может быть единственным основанием, поскольку, во-первых, не является собственно лингвистическим, а во-вторых, не дает возможность учесть все нюансы, вследствие чего имеются формы, одинаково характерные для разных групп рекламных посланий. Например, жанр рекламного объявления возможен и в газете, и на радио, и в интернете и т. п. Кроме того, известны многочисленные примеры, когда один и тот же текст выступает и как радио-, и как телереклама.

1.4. Совершенно иной принцип для выделения жанров рекламы предлагает Е.С. Кара-Мурза, подчеркивая необходимость разграничения «исконно рекламных типов текстов и тех, которые были вовлечены в нее исторически и продолжают вовлекаться - в силу потребности в интенсификации воздействия, в обновлении приемов увещевания» [7, с. 222223]. Действительно, паразитарность рекламы, активно использующей средства воздействия из всех иных дискурсов, является одной из наиболее важных ее характеристик, которая может быть положена в основание классификации. При этом необходимо отметить, что «исконно рекламных типов» достаточно мало (рекламное объявление, афиша, анонс и некоторые другие), в то время как основную массу жанровых форм составляют заимствования из других дискурсов.

При установлении системы жанров считаем необходимым учитывать вид реклами- 
руемого товара, поскольку, как показывают наблюдения, для продвижения разных товаров / услуг используются несколько отличные жанровые формы. Так, на весьма специфический набор форм, характерных для рекламы туристических услуг, указывает Г.С. Атакьян [3], об особенностях рекламирования услуг мобильной связи пишет М.А. Кириленко [8], набор жанров печатной рекламы полиграфического оборудования и технологий представлен в работе Т.Н. Жаворонковой [5] и др. В связи с этим по крайней мере на первом этапе дифференциации рекламных текстов должны быть выявлены особенности их жанрового состава для каждого вида продукции, и только потом можно переходить к созданию общих классификаций.

\section{2. Специфика жанровых форм, используемых в рекламе книги}

С целью раскрытия возможностей применения предложенного подхода перейдем к описанию жанрового состава книжной рекламы в интернете. По форме все рекламные послания на сайтах, торгующих книгами (будь то сайт издательства или книжного магазина), весьма унифицированы. О каждой новой книге сообщаются имя и фамилия автора, название книги, ISBN, год выпуска и количество страниц. Кроме того, по желанию автора текста могут присутствовать и другие сведения: цена, формат издания, тираж и т. п. Основную рекламную нагрузку выполняет аннотация, занимающая центральную часть такого послания.

Классическая аннотация может быть отнесена к традиционным рекламным жанрам. В своем первоначальном виде она регулярно предстает только в презентации учебной литературы:

Учебный комплекс «Линейная алгебра» предназначен для студентов технических и экономических вузов. Он соответствует стандартной программе и содержит 15 лекций, разработки 15 практических занятий с подробным решением типовых примеров и задачами для самостоятельного решения, контрольные вопросы по всем темам (с ответами), варианты контрольных работ. Комплекс отличается от существующих учебных пособий тем, что объединяет в себе функции учебника, сборника задач и репетитора-тренажера и может быть использован как при очной, так и при дистанционной форме обучения (Зимина О. В. Линейная алгебра : учеб. комплекс для вузов. Ростов н/Д : Феникс, 2015).

В этом тексте имеются все типичные для аннотации части: читательский адрес (для студентов технических и экономических вузов), указание на соответствие программе, подробное (и не оценочное) описание содержания книги, характеристика отличий рассматриваемой книги от подобных. В рекламе всех других видов литературы классическая форма аннотации тоже встречается, однако там ее использование весьма ограничено.

Основная масса современных аннотаций модифицируется с целью усиления персуазивной функции текста и принимает форму стилизации под жанры других видов словесности, причем в таком случае используется не только общая структура чужого жанра, но и особенности языкового воплощения текста, свойственные соответствующему функциональному стилю.

2.1. В рекламе произведений художественной литературы можно выделить две основные частотные жанровые формы, выбор которых зависит от характера рекламируемого произведения. Как известно, В.Г. Белинский все произведения художественной литературы разделял на классические (высокохудожественные) и беллетристические (массовые), причем назначение последних, по его мнению, состоит в том, чтобы служить своеобразным посредником между классическим искусством и народом [4].

Для рекламирования литературы, названной В.Г. Белинским беллетристикой, часто используется жанровая форма, обозначаемая в научной литературе как сюжетная аннотация. Она построена на пересказе одной или нескольких сюжетных линий в форме либо прямой, либо несобственно-прямой речи персонажа. Основная задача такой аннотации состоит в том, чтобы познакомить читателя с героями и жанром книги, а также намекнуть на содержание произведения [2, c. 87]. Такие аннотации строятся как стилизации под жанр рассказа, и в них используются элементы художественного функционального стиля: 
Блин, как прикольно проплывать над безмолвной землей на тяжелом корабле, отбрасывая огромную тень. Видеть закаты и рассветы с борта старого дирижабля, наблюдать с боевого поста звезды, смотреть на развалины старых городов поверх стволов тяжелых пулеметов. Как здорово бродить по свету в компании таких же, как и я, удалых парней, которые готовы всякой нечисти рога отстрелить, а бандитам кое-что и покруче... Ну а что до неприятностей и непонятностей, то тяжелые ножи (непростые ножи, ножи некроманта!), а также надежные пистолет и автомат помогут справиться с большинством из них. А с чем не справлюсь я помогут друзья-товарищи. Единственное, в чем не стану просить помощи, - так это в делах личных. Сам разберусь, и пусть потрясные девчонки будут моей головной болью! (Стрельников В. Приключения Василия Ромашкина, бортстрелка и некроманта. М. : АЛЬФА-КНИГА, 2016).

Этот текст построен как прямая речь главного героя и содержит разговорную и жаргонную лексику (блин, прикольно, рога отстрелить, покруче, непонятности, потрясные и т. п.), характеризующую социальное положение и культурный уровень персонажа. Здесь формулируется его жизненное кредо и предъявляются ценности, причем это делается не в обобщенной форме пересказа (что свойственно классическим аннотациям), а с использованием деталей, оценочных суждений и характеристик (что более присуще художественной литературе).

Реклама произведений серьезной (классической, по В.Г. Белинскому) литературы часто строится как стилизация под жанр рецензии:

Все романы Мо Яня - выдающегося китайского писателя современности - получили в мире высокую оценку, и каждый из них демонстрирует глубину и широту его исключительного таланта. «Страна вина» не просто потрясающая книга. Это образец нового писательского стиля, что довольно непросто в наш век. Уникальному стилю Мо Яня присущи великолепная, оригинальная образность, безграничная сила воображения, сплетенная с мифологичностью, и мастерское владение различными формами повествования.

«Страна вина» - это моралите, притча, историческая аллегория и шедевр литературы абсурда, вместе взятые. В то же время это самая яркая и колкая сатира в современной китайской литератуpe. Но в глубоко философском и политическом кон- тексте это роман не только о Китае, и принадлежит он уже не только китайскому искусству, а всему человечеству. Что же касается русскоязычного читателя, то автор уверен: «Раз русским читателям пришелся по душе роман «Мастер и Маргарита» Булгакова, то они примут и мою «Страну вина» (Янь М. Страна вина. СПб. : Амфора, 2012).

В отличие от традиционной аннотации здесь содержится не информация о содержании, построении и назначении произведения, а (как положено в рецензии) его краткий анализ и оценка. Автор этого текста имеет цель сформировать у читателя эстетическое представление о действительности, объяснить суть творческого процесса, содействовать выработке читателем самостоятельных оценок. Таким образом, автор рекламного текста берет на себя право оценивать литературное произведение, то есть выступает в роли критика, что должно повысить доверие к сообщаемым им положительным характеристикам произведения. Вместе с тем автор традиционной рецензии всегда известен, и в соответствии с его репутацией читатель может доверять или не доверять его мнению. Автор рекламы всегда анонимный, причем известно, что он обязан хвалить представляемую книгу, поэтому степень доверия к высказываемым в аннотации мыслям должна соотноситься с указанным статусом автора.

В рекламной рецензии присутствуют средства воздействия, свойственные как собственно рекламе, так и литературной рецензии. С первой ее объединяет наличие положительных оценок, весьма разнообразно и изобретательно характеризующих произведение и автора (выделены в тексте). Как правило, подобные оценки указывают на самую большую степень проявления признака, в связи с чем могут быть охарактеризованы как гипербола. Со второй рассматриваемую рекламную форму объединяет наличие большого количества литературоведческих терминов (моралите, притча, историческая аллегория, литература абсурда, сатира), а также сопоставление с романом М. Булгакова, широко известным в России и любимым читателями.

Как правило, стилизация под жанр рецензии отличается многообразием используемых изобразительно-выразительных средств: метафор (Роман «Край навылет» Томаса Пин- 
чона - настоящий деликатес для литературных гурманов), метонимий (Сергея Носова не интересуют звоны военной меди), антитез («Осень Средневековья»-не только гибель, но и надежда. Ностальгическая устремленность в священное проилое европейской культуры - оборотная сторона надежды на будущее), сравнений (Эта бесконечно притягательная в своем многообразии словесная ткань, как жнвая, пульсирует в многомерной структуре книги) и др., что в целом не характерно для жанра аннотации. В таких рецензиях могут употребляться языковые единицы с разной функционально-стилистической окраской, а также общекнижная и возвышенная лексика. Эта черта отражает особенности публицистического стиля, доминантой которого является принципиальное стилистическое многообразие. При этом сочетание указанных средств воздействия типично для аналитического подстиля, к которому и относится жанр рецензии.

2.2. В рекламе произведений религиозной тематики присутствует гораздо более осознанное стремление к стилизации под религиозный функциональный стиль, чем в рекламе произведений художественной литературы. Здесь используется большое количество слов, имеющих функционально-стилевую окраску религиозного стиля:

На протяжении всей истории Церкви множество духовных писателей, богословов и песнописцев в торжественных гимнах и смиренных строках прозы прославляли «высшую небес и чистую светлостей солнечных Владычицу мира». Новая книга Светланы Рыбаковой - еще один труд, воздающий хвалу Матери Божией, Чыи бесчисленные чудеса и помощь роду человеческому не перестают удивлять и вызывать благоговейный трепет и восхищение в каждом верующем сердце (Рыбакова С. Н. Чудеса и судьбы икон Божией Матери в ХХ веке. - М. : Лепта, 2016);

а также типы аргументов, характерные для религиозной литературы, например, ссылки на авторитетные высказывания столпов церкви:

Жанр акафиста - церковного гимна, прославляющего Господа Бога, Пречистую Богородицу и святых - был с давних пор любим верующими на
Руси. Об этом свидетельствуют не только многочисленные рукописи и книги, но и жития русских святых. Свт. Иннокентий Херсонский отмечал, что «действие сих акафистов на народ было чрезвычайно сильное и благотворное. Акафистное пение дарует чувство духовной бодрости и радости, придает сил» ( Акафистник. М. : Лепта, 2014).

В рекламе книг с религиозной тематикой доминирует стилизация под жанр проповеди. Как отмечает Е.М. Морозов, «по своему характеру проповедь бывает поучительной, наставительной и обличительной. Основанием для такой классификации являются слова из пастырского послания апостола Павла: “Проповедуй слово, настой во время и не во время, обличай, запрещай, увещевай со всяким долготерпением и назиданием"» $[9$, с. 60]. В соответствии с этим и стилизации под жанр проповеди могут приобретать три формы.

С помощью посланий, стилизованных под проповедь поучительного характера, копирайтер стремится напомнить читателям основные постулаты вероучения, в связи с чем тексты таких аннотаций состоят из двух частей. В первой части предъявляется фрагмент религиозного знания:

На небесах у каждого христианина есть свой небесный покровитель - святой, в честь которого он назван. Святые - это люди, жизнь которых является для нас примером веры, любви, добра и мудрости. Жития святых - это тот источник, к которому важно прикоснуться в самом раннем детстве.

Во второй части в форме аннотации рассказывается о назначении, характере содержания и других особенностях книги, а также читательском адресе и пользе от прочтения книги:

В данном издании жития святых изложены кратко и доступно детскому пониманию. Ваш ребенок, который делает лишь первые шаги на пути веры, с радостью познакомится с героями этой прекрасно иллюстрированной книги. Из этой книги дети узнают, почему святителя Николая называют Чудотворцем, какая святая стала духовной матерью русского народа, кто благословил на подвиг князя Дмитрия Донского перед Куликовской битвой, кто основал Марфо-Мариинскую обитель милосердия (Пушкина Д. В., Бакулина И. В. Небесные заступники. Жития святых для мальчиков и девочек, а также пап и мам. М. : Даръ, 2016). 
Стилизация под проповедь наставительного характера чаще всего используется в виде вкраплений соответствующих элементов в текст аннотации. Однако бывают рекламные тексты, полностью являющиеся стилизацией под проповедь:

Кто владеет языком своим, тот владеет всем телом. Иногда молчание полезнее слов, иногда слова лучше молчания: есть время молчать, и бывает время говорить. Разумный человек сначала обдумывает мысль свою и каждое слово обращает в сердце своем и, если найдет его полезным, износит из сердца и передает языку. Как кормчий осмотрительно направляет корабль вперед, чтобы не наткнуться на подводный камень или скалу какую, так и муж разумный пусть тщательно рассматривает, что ему должно делать и чего убегать, избирая для себя полезное. Почему так сладостна надежда, и всякие дела при ней бывают легки? - Тех, кто ревность свою, и пламенность, и любовь к Богу сохранил неугасимою и не перестает каждый день прилагать огонь к огню, усердие к усердию и желание к желанию. Но «не стремись двигаться быстpee, чем это угодно воле Божией; не спеши настолько, чтобы стараться обогнать ведущий тебя Промысл. Однако я не говорю, что ты не должен быть ревностным», - к этому совету Исаака Сирина и прислушался автор книги, муж, влюбленный в море, нашедший свою путеводную звезду, неожиданно для себя пустившийся в необычное плавание, среди удивительных мыслей и слов, многие из которых стоят целых книг (Микрюков А. В открытом море мыслей. М. : Sanktum, 2013).

Главным показателем стилизации именно под проповедь является наличие в этом тексте воспитательной интенции, внушение определенных постулатов правильного поведения. Языковыми показателями стилизации здесь является использование лексики, обладающей функционально-стилевой окраской религиозного стиля (к Богу, угодно воле Божией, Промысл), лексики, обладающей возвышенной эмоционально-стилистической окраской (пламенность, неугасимылй, ревностный), устаревшей лексики (износит из сердияа, кормчий, чего убегать). К синтаксическим особенностям, характеризующим проповедь, относятся синтаксический параллелизм и особый порядок слов, выражающийся в перемещении ремы с конечной позиции в начальную, а также в инверсии частей предложения. Сюда же относится и употребление сравни- тельного оборота (как кормчий.., так и муж разумныли), цитаты из трудов Исаака Сирина, риторических вопросов, используемых для активизации внимания читателей.

Стилизация под проповедь-обличение отражает существенную особенность презентации религиозной литературы. Только здесь возможны рекламные тексты с элементами критики, поскольку именно в указанной области критика противников, несогласных, отступников и т. п. имеет положительную коннотацию и не воспринимается как неэтичная:

В настоящее время христианская цивилизация находится в глубоком кризисе, вызванном, в первую очередь, тем, что церковные иерархи христианской религии, а вместе с ними сотни миллионов верующих слишком далеко ушли от учения Господа нашего Иисуса Христа. К тому же, первосвященники переругались между собой и фактически ассоциировали себя со светской властью. А последняя стала по факту атеистической, разорвав даже видимую связь с Богом. В силу этого они окончательно запутались в противоречиях жизни, утеряли истину и не нашли путь, которые есть только у Бога. Продолжение современного положения грозит мировой цивилизации крахом. Положение надо исправлять, но, похоже, ни светские правители, ни церковные пока этого так и не осознали. Кажется, что только глава католической церкви этим озабочен, а остальные, что в церкви, что в миру, полагают, что все, как обычно, утрясется само собой. Что касается массы верующих, то им нужно понять, что уповать следует не на церковь, а на Бога, путь к которому каждый может сам найти в Евангелие и в своей душе и в сердце (Ильин Ю. Христианская цивилизация II: поиск истины и пути. М. : Sanktum, 2016).

Показателем этой формы проповеди является сочетание в одном тексте лексем, обладающих функционально-стилевой окраской религиозного стиля (церковные иерархи, от учения Господа нашего Иисуса Христа, первосвященники, глава католической церкви), и лексем, не свойственных этому стилю, выражающих преимущественно отрицательное значение: именно с помощью такой лексики описываются осуждаемые действия и явления (переругались, запутались в противоречиях, крах, утрясется само собой).

2.3. Реклама нехудожественных произведений о бизнесе, здоровом образе 
жизни, психологии и т. п. адресуется любознательным читателям, не специалистам в указанной области (или специалистам-практикам). В настоящее время выходит много подобной литературы. Аннотации к таким изданиям стилизуются под жанровые формы, характерные для тех областей, где находят применение эти книги.

Консультация. Чаще всего это та форма, которую использует тренер, проводящий разнообразные (и модные в настоящее время) тренинги (по психологии, менеджменту и т. п.). В аннотации в форме консультации речь идет о том, что должен делать адресат, чтобы получить желаемый результат (похудеть, выйти замуж, добиться успеха в жизни и т. п.):

Вы перегружены делами? Скорее всего, да. У всех нас много дел, и часто к концу дня мы чувствуем себя уставшими - ведь столько всего пришлось переделать! Но так ли важны были все эти дела? Время осознать: вы никогда не сможете успеть все. Нужно смириться с тем, что многие вещи не будут сделаны никогда. Вместо попыток справиться со своим бесконечным списком дел попробуйте другой подход - делайте только важное. Совсем скоро у вас появится время, чтобы свободно вздохнуть и оглядеться, наслаждаться моментом. Вы избавитесь от бесконечного круговорота рутины, сможете находить более глубокие и креативные решения рабочих и личных проблем, изыскивать новые возможности - и в конечном счете станете счастливее (О’Коннел Ф. Делай меньше. М. : Манн, Иванов и Фербер, 2016).

В таких текстах активно используются всеразновидности диалогизма (как прямые, так и косвенные). Их композиция тоже вполне традиционна: в начале текста формулируется острая проблема, мешающая жить адресату, затем дается обещание предложить простой способ ее решения, сопровождаемое подробным описанием тех выгод и преимуществ, которые при этом можно получить.

В некоторых случаях эта жанровая форма может быть усеченной: весь текст рекламного послания ограничивается одним описанием того результата, которого может достичь читатель, если изучит книгу. Поскольку это такой результат, о котором, по мнению автора, страстно мечтает адресат, первая часть с обоснованием проблемы не требуется:
Итак, займемся модой! После завершения работы над этой книгой ты станешь настоящим дизайнером собственного бренда со своим уникальным стилем. Тебе предстоит создать потрясающие наряды для каждого сезона, изучить моду прошлого с ее неизменным винтажным шиком и придумать гламурные образы для недель моды по всему миру. Добавляй элегантные детали при помощи черной ручки, используй цветные карандаши и фломастеры для создания совершенных оттенков. Вдохновляйся, раскрашивай и придумывай стильные штучки! (Мой волшебный мир моды и красоты. Раскраска - вдохновение. М. : ЭКСМО, 2016).

Здесь в качестве желаемого результата провозглашается обещание стать настоящим дизайнером собственного бренда со своим уникальным стилем, а далее перечисляются те шаги, которые предстоит совершить, чтобы его достичь. При этом специально подчеркивается привлекательность результата, усиливающая персуазивную функцию текста.

Подборка отзывов. В рекламе любых книг мнение людей с аналогичными вкусами или потребностями является решающим аргументом при принятии решения о покупке. В связи с этим одним из наиболее активных видов аргументов является ссылка на востребованность этой книги у целевой аудитории: раз всем любителям детективов нравится этот детектив, значит, он лучше (интереснее), чем другие детективы. Способы реализации этого аргумента могут быть самые разные: указание на то, что это бестселлер (по рейтингу популярности), сообщение об огромном тираже, которым издана книга и т. п.: Мировой бестселлер для всех возрастов. Притча, ставшая классикой. Она входит в икольные программы многих стран мира. Ее читают детям в дошкольных учреждениях и цитируют во время проповедей.

Однако наиболее действенным этот аргумент становится тогда, когда облекается в форму отзыва о книге. Отзыв используется и в рекламе художественной литературы, не образуя, однако, отдельного жанра: обычно один, максимум два коротких отзыва помещаются в конце аннотации и являются эмоциональным завершением (своего рода «восклицательным знаком») текста. Напротив, в литературе описываемой группы подборка отзывов высту- 
пает самостоятельным компонентом рекламы, призванным доказать то, что описываемая в книге технология эффективна и одобрена представителями целевого адресата книги. Вместе с тем читатель не может определить, существуют ли в реальности те люди, которым приписываются приводимые мнения. Вполне возможен вариант, когда все эти высказывания составлены самим копирайтером. Именно поэтому мы относим эту форму к стилизациям под жанр отзыва. В качестве иллюстрации приведем текст рекламы книги Л. Хоманна «Бизнес-игры: создание революционных продуктов с помощью клиентов» (СПб. : Символ Плюс, 2008):

Что самое трудное в инновациях? Точно предсказать, чего хотят клиенты, что им нужно и за что они готовы платить деньги. Даже если спросить их об этом прямо, они часто не могут объяснить, чего хотят. Теперь у нас есть революционное решение: инновационные бизнес-игры. Основываясь на своем опыте консалтинга в стратегическом планировании программных продуктов и управления продуктами, Люк Хоманн разработал двенадцать игр, с помощью которых вы раскроете подлинные и скрытые потребности и желания ваших клиентов. Вы держите в руках незаменимое пособие для всех, кто стремится более успешно управлять ориентированной на пользователя разработкой продукта: ведущих технологов и разработчиков, маркетологов и старших администраторов.

«Бизнес-игры» - одна из тех книг, об огромной пользе которых вы можете и не догадываться, пока не прочтете их, а потом начинаете недоумевать, как вы могли обходиться без них раньше. Если вы не хотите остаться завтра без клиентов, то прочтите эту книгу и сыграйте в эти игры! (Майкл Дж. Хантер).

Люк Хоманн приводит критические отзывы своих студентов о SD West в своем учебном пособии по инновационным играм. Я получила от группы очень много отзывов. Если вы хотите не потерять свой продукт, нет лучшего источника вдохновения (и информации), чем ваш клиент (Тамара Картер).

Книга Люка восполнила существенный пробел в литературе, посвященной этой теме, - есть слишком много книг о том, как создавать продукт, но слишком мало о том, чем руководствоваться в первую очередь (Элистер Кокберн).

Всего в этой подборке приведено 25 отзывов, призванных доказать, что люди, кото- рых обучал автор книги, остались довольны описываемой технологией.

\section{3. Выводы}

Итак, реклама книги является особой областью рекламного дискурса. Здесь отсутствуют жанры, традиционно выделяемые исследователями, основной формой продвижения книжной продукции является модифицированная аннотация, помещаемая на сайтах издательств, книжных магазинов и т. п. Для усиления персуазивной функции текста аннотации придается форма стилизации под жанры иных видов словесности. Можно выделить две основные группы таких стилизаций:

- стилизация под жанры, характерные для того вида литературы, к которому относится сама книга. Так, реклама художественной литературы облекается в форму рассказа, реклама религиозной литературы - в форму проповеди и т. п.;

- стилизация под жанры, прямо предназначенные для одобрения содержания рекламируемого вида литературы. Реклама художественного произведения приобретает форму рецензии, поскольку именно по рецензиям на новые книги вдумчивый читатель определяет, какую именно из новинок стоит покупать. Реклама практических пособий по менеджменту подается в форме отзывов клиентов, уже опробовавших предлагаемые методики и т. п.

Аналогичным образом строится и реклама других видов литературы, не рассматривавшихся в данной статье. Например, реклама научно-популярной литературы часто облекается в форму научно-популярного очер$\kappa a$; реклама детской литературы стилизуется под консультащию педагога или психолога, который разъясняет родителям, какие выгоды и преимущества они получат, если используют книгу в процессе воспитания и обучения ребенка (см. об этом: [1]).

Кроме этого, в редких случаях используются жанры, напрямую не связанные с особенностями рекламируемого вида литературы. Эти жанровые формы используются исключительно для активизации внимания адресата, не образуют устойчивой системы (имеют случайный характер). 


\section{СПИСОК ЛИТЕРАТУРЫ}

1. Анисимова, Т. В. Особенности отбора аргументов в рекламе книги / Т. В. Анисимова // Научный журнал «Рухіs». - 2016. - № 3. - С. 90-99.

2. Анисимова, Т. В. Реклама в издательском деле / Т. В. Анисимова, И. В. Ярова. - Ижевск : КнигоГрад, 2011. -200 с.

3. Атакьян, Г. С. Жанровая палитра рекламного и публицистического дискурсов / Г. С. Атакьян // Наука-2007 : ежегод. сб. ст. ученых и аспирантов АГУ. - Майкоп : Изд-во АГУ, 2008. - Ч. 2. - С. 6-10.

4. Белинский, В. Г. Опыт истории русской литературы / В. Г. Белинский // Собрание сочинений : в 9 т. - М. : Худож. лит., 1981. - Т. 7. - С. 324-365.

5. Жаворонкова, Т. Н. Механизм формирования жанрово-тематической модели печатных рекламных сообщений в условиях отраслевых рынков / Т. Н. Жаворонкова, Т. С. Васильева. - М. : Моск. гос. ун-т печати, 2009. - 100 с.

6. Золина, О. Е. Синтаксические свойства языка и их стилистическая роль в рекламных текстах : дис. ... канд. филол. наук / Золина Оксана Евгеньева. - М., 2006. -179 с.

7. Кара-Мурза, Е. С. Реклама: жанр, функциональный стиль, дискурс? / Е. С. Кара-Мурза // Стереотипность и творчество в тексте : межвуз. сб. науч. тр. / под ред. М. П. Котюровой. - Пермь : Изд-во Перм. ун-та, 2010. - С. 220-231.

8. Кириленко, М. А. Жанрово-стилистические особенности рекламы мобильной связи : дис. ... канд. филол. наук / Кириленко Мария Александровна. - М., 2004. -173 c.

9. Морозов, Е. М. Язык современной церковной проповеди православного священнослужителя / Е. М. Морозов // Язык и культура. - 2015. № 2. - С. 58-63.

10. Нерознак, В. П. Язык рекламы / В. П. Нерознак // Эффективная коммуникация: история, теория, практика : слов.-справ. - М. : КРПА Олимп, 2005. - C. 711-713.

11. Реклама: палитра жанров / В. В. Ученова, С. А. Шомова, Т. Э. Гринберг, К. В. Конаныхин. М. : Гелла-принт, 2004. - 238 с.

\section{REFERENCES}

1. Anisimova T.V. Osobennosti otbora argumentov v reklame knigi [Features of Arguments Selection in Book Advertising]. Nauchnyy zhurnal «Pyxis», 2016, no. 3, pp. 90-99.
2. Anisimova T.V., Yarova I.V. Reklama v izdatelskom dele [Advertising in Publishing Business]. Izhevsk, KnigoGrad Publ., 2011. 200 p.

3. Atakyan G.S. Zhanrovaya palitra reklamnogo i publitsisticheskogo diskursov [The Genre Range of Advertising and Journalism Discourses]. Nauka2007: ezhegod. sb. st. uchenykh i aspirantov $A G U$. Ch. 2 [Science-2007. The Annual Collection of Articles by Scientists and Postgraduate Students of ASU. Part 2]. Maykop, Izd-vo AGU, 2008, pp. 6-10.

4. Belinskiy V.G. Opyt istorii russkoy literatury [Experience of the History of Russian Literature]. Sobranie. sochineniy: v 9 t. T 7 [Collected works. In 9 vols. Vol. 7]. Moscow, Khudozh. lit. Publ., 1981, pp. 324-365.

5. Zhavoronkova T.N., Vasilyeva T.S. Mekhanizm formirovaniya zhanrovo-tematicheskoy modeli pechatnykh reklamnykh soobshcheniy $v$ usloviyakh otraslevykh rynkov [The Mechanism of Formation of Genre-Themed Model of Printed Advertising Messages in Conditions of the Industrial Markets]. Moscow, Moskovskiy gos. un-t pechati Publ., 2009. 100 p.

6. Zolina O.E. Sintaksicheskie svoystva yazyka $i$ ikh stilisticheskaya rol $v$ reklamnykh tekstakh: dis. ... kand. filol. nauk [Syntactic Properties of Language and Their Stylistic Role in Advertising Texts. Cand. philol. sci. diss.]. Moscow, 2006. 179 p.

7. Kara-Murza E.S. Reklama: zhanr, funktsionalnyy stil, diskurs? [Advertising: Genre, Functional Style, Discourse?]. Kotyurova M.P., ed. Stereotipnost $i$ tvorchestvo $v$ tekste: mezhvuz. sb. nauchnyh trudov [Stereotype and Creativity in the Text]. Perm, Izd-vo Permskogo un-ta, 2010, pp. 220-231.

8. Kirilenko M.A. Zhanrovo-stilisticheskie osobennosti reklamy mobilnoy svyazi: dis. ... kand. filol. nauk [Genre and Stylistic Peculiarities of Advertising Mobile Communication. Cand. philol. sci. diss.]. Moscow, 2004. 173 p.

9. Morozov E.M. Yazyk sovremennoy tserkovnoy propovedi pravoslavnogo svyashchennosluzhitelya [The Language of Contemporary Church Sermon by an Orthodox Priest]. Yazyk i kultura, 2015, no. 2, pp. 58-63.

10. Neroznak V.P. Yazyk reklamy [The Language of Advertising]. Effektivnaya kommunikatsiya: istoriya, teoriya, praktika: slov.-sprav. [Effective Communication: History, Theory, Practice: DictionaryReference Book]. Moscow, KRPA Olimp Publ., 2005, pp. 711-713.

11. Uchenova V.V., Shomova S.A., Grinberg T.E., Konanykhin K.V. Reklama: Palitra zhanrov [Advertising: The Range of Genres]. Moscow, Gellaprint Publ., 2004. 238 p. 


\section{Information About the Author}

Tatyana V. Anisimova, Doctor of Sciences (Philology), Professor, Department of Journalism and Media Communications, Volgograd State University, Prosp. Universitetsky, 100, 400062 Volgograd, Russian Federation, atvritor@yandex.ru, stilvolsu@mail.ru.

\section{Информация об авторе}

Татьяна Валентиновна Анисимова, доктор филологических наук, профессор кафедры журналистики и медиакоммуникаций, Волгоградский государственный университет, просп. Университетский, 100, 400062 г. Волгоград, Российская Федерация, atvritor@yandex.ru, stilvolsu@mail.ru. 